\title{
Evaluation of methods for the quantification of ether extract contents in forage and cattle feces
}

\author{
MARCÍLIA M. BARBOSA ${ }^{1}$, EDENIO DETMANN ${ }^{1}$, SEBASTIÃO C. VALADARES FILHO ${ }^{1}$, KELLY \\ S.C. DETMANN ${ }^{2}$, MARCIA O. FRANCO ${ }^{3}$, ERICK D. BATISTA ${ }^{4}$ and GABRIEL C. ROCHA ${ }^{1}$ \\ ${ }^{1}$ Universidade Federal Viçosa, Departamento de Zootecnia, Av. P.H. Rolfs, s/n, 36570-900 Viçosa, MG, Brazil \\ ${ }^{2}$ Universidade Federal de Viçosa, Departamento de Biologia Vegetal, Av. P.H. Rolfs, s/n, 36570-900 Viçosa, MG, Brazil \\ ${ }^{3}$ Department of Agricultural Research of Northern Sweden, Swedish University of \\ Agricultural Sciences, Skogsmarksgränd 901 93, Umeå, Sweden \\ ${ }^{4}$ Universidade Federal de Mato Grosso, Instituto de Ciências Agrárias e Ambientais, Av. \\ Alexandre Ferronato, 1200, Setor Industrial, 78557-267 Sinop, MT, Brazil \\ Manuscript received on October 21, 2016; accepted for publication on January 5, 2017
}

\begin{abstract}
The objective of this study was to compare the estimates of ether extract (EE) contents obtained by the Randall method and by the high-temperature method of the American Oil Chemist's Society (AOCS; Am $5-04)$ in forages $(n=20)$ and cattle feces $(n=15)$. The EE contents were quantified by using the Randall extraction or AOCS method and XT4 filter bags or cartridges made of qualitative filter paper $\left(80 \mathrm{~g} / \mathrm{m}^{2}\right)$ as containers for the samples. It was also evaluated the loss of particles, and concentration of residual chlorophyll after extraction and the recovery of protein and minerals in the material subjected to extraction. Significant interaction was observed between extraction method and material for EE contents. The EE estimates using the AOCS method were higher, mainly in forages. No loss of particles was observed with different containers. The chlorophyll contents in the residues of cattle feces were not affected by the extraction method; however, residual chlorophyll was lower using the AOCS method in forages. There was complete recovery of the protein and ash after extraction. The results suggest that AOCS method produces higher estimates of EE contents in forages and cattle feces, possibly by providing greater extraction of non-fatty EE.
\end{abstract}

Key words: crude fat, feed analysis, filter bags, non-polar compounds.

\section{INTRODUCTION}

The ether extract (EE) have heterogeneous composition and is formed by lipids (galactolipids, triglycerides and phospholipids) and all other non-polar compounds that can be extracted by solvents, such as phosphatides, steroids, pigments, fat-soluble vitamins, and waxes. Thus, the gravimetrically extracted residue is properly termed crude fat, due to the discrepancy between the analytical and biochemical concepts of lipids (Van Soest 1994, Palmquist and Jenkins 2003, Silva et al. 2011).

Correspondence to: Edenio Detmann

E-mail: detmann@ufv.br 
Among the gravimetric methods for assessing the EE concentration, the submersion method, also known as the Soxtec or Randall method, has been recommended for the evaluation of animal feeds (Thiex et al. 2003, Detmann et al. 2012). This method is based on the extraction of the non-polar fraction of feed in three steps (immersion, washing and drying) and was originally proposed to decrease the analysis time and increase the operational efficiency compared with the Soxhlet method (Palmquist and Jenkins 2003). The accuracy and the ruggedness of this method were evaluated by Thiex et al. (2003), whose study was used as support for adoption of the Randall method as the official method of the Association of Official Analytical Chemists (AOAC).

More recently, the American Oil Chemist's Society (AOCS) adopted an official method for assessing EE contents in foods using filter bags and an extraction under high temperature and pressure. This method is not time-consuming and presents high operational efficiency. However, Silva et al. (2011) compared the estimates of EE contents obtained with the official method proposed by the AOCS and the Goldfish method and concluded that the AOCS method overestimates the EE concentration in forage and cattle feces samples as a possible result of the higher extraction of non-fatty material.

The EE is an analytical concept that is defined by the method itself (Palmquist and Jenkins 2003). However, there must be consistency between the estimates obtained by different methods so that comparisons between studies can be performed with high ruggedness. Thus, studies should be conducted to determine the correct understanding of the analytic entities produced by different methods and broadly classified as EE.

Thus, the objective of the present study was to compare the estimates of ether extract contents obtained by the Randall method and by the high-temperature method recommended by the AOCS in forages and cattle feces.

\section{MATERIALS AND METHODS}

\section{LOCATION AND SAMPLES}

The evaluations were performed at the Laboratory of Animal Nutrition at Department of Animal Science, Universidade Federal de Viçosa, Viçosa, Brazil, using samples of tropical grasses and legumes and cattle feces.

Ten fresh grass samples and ten fresh legume samples were collected. The following grasses were used: Brachiaria decumbens, Brachiaria brizantha cv. Marandu, Brachiaria brizantha cv. Piatã, Brachiaria brizantha cv. Xaraés, Panicum maximum cv. Tanzania, Panicum maximum cv. Massai, Panicum maximum cv. Colonião, Panicum maximum cv. Mombaça and Tifton-68 and Tifton-85 grasses (Cynodon sp.). Additionally, the following legumes were evaluated: Stylosanthes sp. cv. Campo Grande, Cajanus cajan, Calopogonium mucunoides, Centrosema pubescens, Leucaena leucocephala, Gliricidia sepium, Pueraria phaseoloides, Neonotonia wightii, Arachis pintoi and Stylosanthes sp. cv. Minerão, totaling 20 samples.

The fecal samples were collected from feedlot $(n=5)$ and grazing $(n=5)$ beef cattle experiments and from lactating cows $(\mathrm{n}=5)$, totaling 15 samples.

All samples were freeze-dried and processed in a knife mill $(1 \mathrm{~mm})$. The residual moisture was obtained by oven-drying the samples at $105^{\circ} \mathrm{C}$ for $16 \mathrm{~h}$, which was used to express the EE contents on a dry matter (DM) basis. 


\section{QUANTIFICATION OF THE ETHER EXTRACT CONTENTS}

To assess the estimates of the EE contents, all of the samples of forage and cattle feces were used.

Analyses were conducted following the Randall method (AOAC method 2003.05; 4), replacing the diethyl ether with petroleum ether (petroleum ether PA, boiling point 30-60 ${ }^{\circ}$, Vetec 188.06 , SigmaAldrich, São Paulo, SP, Brazil), and the AOCS high-temperature method (AOCS Method Am 5-04; 6), also using petroleum ether. The assessments for both methods were conducted using two types of containers for sample placement: cartridges made of qualitative filter paper $\left(80 \mathrm{~g} / \mathrm{m}^{2}\right)$ and XT4 filter bags (Ankom $\left.{ }^{\circledR}\right)$. The analyses performed according to the Randall and AOCS methods were conducted using TE-044-8/50 (Tecnal ${ }^{\circledR}$ Equipamentos, Piracicaba, SP, Brazil) and XT15 (Ankom ${ }^{\circledR}$ Technology, Macedon, NY, USA) fat analyzers, respectively. The petroleum ether was used for both extraction methods to avoid confounding associated with using different solvents.

For the Randall method evaluations, using cartridges of qualitative filter paper, approximately $2 \mathrm{~g}$ of each sample were weighed on a sheet of qualitative filter paper $\left(80 \mathrm{~g} / \mathrm{m}^{2}\right)$ and then wrapped in a second sheet of the same paper. For the XT4 filter bags, approximately $1 \mathrm{~g}$ of each sample was placed in a filter bag, which was then heat-sealed.

The beakers of the Tecnal ${ }^{\circledR}$ TE-044-8/50 fat extractor were previously cleaned, oven-dried $\left(105^{\circ} \mathrm{C} / 16\right.$ h), placed in a desiccator and weighed. Prior to the extraction, the cartridges and filter bags containing the samples were placed in their respective cups and oven-dried $\left(105^{\circ} \mathrm{C} / 3 \mathrm{~h}\right)$ to decrease the moisture content.

The cartridges or the filter bags were attached to the metal bracket of the fat analyzer. Subsequently, $100 \mathrm{~mL}$ of petroleum ether were added to each beaker, which were then attached to the condenser and set into the heating unit.

The samples were immersed in the boiling solvent for $30 \mathrm{~min}$. Then, the samples were suspended, and the washing stage was performed for $60 \mathrm{~min}$ at a drip rate of 3-5 drops/second.

After washing stage, the ether was extracted by means of a recycling mechanism that is characteristic of the equipment, until a thin layer of ether ( 1 to $2 \mathrm{~mm}$ ) was present in the bottom of the beaker. After this procedure, the beakers were oven-dried $\left(105^{\circ} \mathrm{C} / 30 \mathrm{~min}\right)$ for the evaporation of the residual ether, placed in a desiccator and weighed. The EE was estimated by the weight gain of the beaker.

To perform the evaluations according to the AOCS method, the samples were placed in cartridges of qualitative filter paper or XT4 filter bags, as described for the Randall method. The samples were ovendried $\left(105^{\circ} \mathrm{C} / 3 \mathrm{~h}\right)$ and were then placed in a desiccator and weighed to obtain the pre-extraction weight.

The samples were placed in the Ankom ${ }^{\circledR}$ XT15 analyzer (ten samples in filter bags or six samples in cartridges were analyzed simultaneously). The extraction was conducted for $50 \mathrm{~min}$ at $90^{\circ} \mathrm{C}$. After the extraction, the samples were removed from the analyzer and oven-dried $\left(105^{\circ} \mathrm{C} / 30 \mathrm{~min}\right)$ and were then placed in a desiccator and weighed. The EE was estimated by the weight loss (AOCS 2009).

The EE contents (g/kg DM) were subjected to analysis of variance, according to the model:

$$
Y_{i j k l}=\mu+G_{i}+S_{(i) j}+M_{k}+C_{l}+G M_{i k}+G C_{i l}+M C_{k l}+G M C_{i k l}+\varepsilon_{i j k l}
$$

where $\mu$ is the general constant, $G_{i}$ is the fixed effect of the group of samples $i$ (forage or feces), $S_{(i) j}$ is the random effect of the sample $\mathrm{j}$ within group $\mathrm{i}, \mathrm{M}_{\mathrm{k}}$ is the fixed effect of the extraction method $\mathrm{k}$ (Randall or 
AOCS), $C_{1}$ is the fixed effect of the container 1 (cartridges or or filter bags), $\mathrm{GM}_{\mathrm{ik}}, \mathrm{GC}_{\mathrm{il}}, \mathrm{MC}_{\mathrm{kl}}$, and $\mathrm{GMC}_{\mathrm{ikl}}$ are the interactions among the main effects (fixed effects), and $\varepsilon_{\mathrm{ijkl}}$ is the random error.

The analyses were performed using the MIXED procedure of SAS $9.3(\alpha=0.05)$.

EVALUATION OF THE LOSS OF PARTICLES FROM SAMPLES ACCORDING TO THE DIFFERENT CONTAINERS

To evaluate the loss of particles, ten forage samples (five grasses and five legumes) and five feces samples were randomly chosen. Each sample was placed in a cartridge of qualitative filter paper and also in a XT4 filter bag, as described in section Quantification of the ether extract contents.

The cartridges or the filter bags were individually placed, together with a magnetic bar, into reservoir flasks of Soxhlet fat extractors, to which $500 \mathrm{~mL}$ of petroleum ether were added. The Soxhlet extractors were connected over hot plates (TE-0851, Tecnal® Equipmentos, Piracicaba, SP, Brazil) and heated to $95^{\circ} \mathrm{C}$. After reaching the extraction temperature, the material was kept under stirring $(100 \mathrm{rpm})$ for $30 \mathrm{~min}$.

Sheets of a quantitative filter paper (Whatman \#41) had previously been oven-dried $\left(105^{\circ} \mathrm{C} / 30 \mathrm{~min}\right.$ ), placed in a desiccator and weighed.

After the extraction period, the contents of the reservoirs were filtered using the previously weighed filter papers. After filtration, the filter papers were again oven-dried $\left(105^{\circ} \mathrm{C} / 30 \mathrm{~min}\right)$, placed in a desiccator and weighed. The loss of particles was estimated by the weight gain of the filter paper.

The results were subjected to analysis of variance according to the following model:

$$
Y_{i j k}=\mu+G_{i}+S_{(i) j}+C_{k}+G C_{i k}+\varepsilon_{i j k}
$$

where $\mu$ is the general constant, $G_{i}$ is the fixed effect of group of samples $i$ (forage or feces), $S_{(i) j}$ is the random effect of the sample $\mathrm{j}$ within group $\mathrm{i}, \mathrm{C}_{\mathrm{k}}$ is the fixed effect of the container $\mathrm{k}$ (cartridges or filter bags), $\mathrm{GC}_{\mathrm{ik}}$ is the interaction between the main effects (fixed effect), and $\varepsilon_{\mathrm{ijk}}=$ is the random error.

The analyses were performed using the MIXED procedure of SAS $9.3(\alpha=0.05)$.

\section{EVALUATION OF THE RESIDUAL CONCENTRATION OF CHLOROPHYLL}

To assess the residual chlorophyll concentration, ten forage samples (five grasses and five legumes) and five feces samples were randomly chosen. Aliquots of each sample were extracted using the Randall and AOCS methods, with cartridges of qualitative filter paper or XT4 filter bags, as described in section Quantification of the ether extract contents. After extraction, the defatted residues were placed in polyethylene bottles kept in the dark.

Subsequently, aliquots of approximately $100 \mathrm{mg}$ of all of the defatted residues and non-extracted samples were placed in porcelain crucibles, and approximately $50 \mathrm{mg}$ of calcium carbonate and $5 \mathrm{~mL}$ of acetone solution $(800 \mathrm{~mL} / \mathrm{L})$ were added. The mixture was then homogenized with a glass rod and subsequently transferred into a $25 \mathrm{~mL}$ volumetric flask. The transfer was performed using quantitative filter paper (Whatman \#41). Acetone solution $(800 \mathrm{~mL} / \mathrm{L})$ was used to wash material and to complete the flask volume $(25 \mathrm{~mL})$. The solutions were kept in the dark by wrapping the flask in aluminum foil.

The absorbance of the solutions was assessed at $646.8 \mathrm{~nm}$ and $663.2 \mathrm{~nm}$ wavelengths. The "zero" absorbance reading was obtained using acetone solution $(800 \mathrm{~mL} / \mathrm{L})$.

The total chlorophyll concentration in the solutions was obtained according to Lichthenthaler (1987): 


\section{Clor $T=7.15 \times A_{663.2}+18.71 \times A_{646.8}$}

where ClorT is the concentration of total chlorophyll in the solution $\left(\mathrm{mg} \mathrm{L}^{-1}\right)$, and $\mathrm{A}_{646.8}$ and $\mathrm{A}_{663.2}$ are the absorbencies of the respective wavelengths.

The total chlorophyll contents in the non-extracted samples and residues ( $\mathrm{mg} / \mathrm{kg} \mathrm{DM})$ were subjected to analysis of variance according to the model:

$$
Y_{i j k}=\mu+G_{i}+S_{(i) j}+M_{k}+G M_{i k}+\varepsilon_{i j k}
$$

where $\mu$ is the general constant, $G_{i}$ is the fixed effect of the group of samples $i$ (forage or feces), $S_{(i)}$ $\mathrm{j}$ is the random effect of sample $\mathrm{j}$ within group $\mathrm{i}, \mathrm{M}_{\mathrm{k}}$ is the fixed effect of the evaluated material $\mathrm{k}$ [nonextracted samples or the residues obtained by the combination of extraction methods (Randall or AOCS) and containers (cartridges or filter bags)], $\mathrm{GM}_{\mathrm{ik}}$ is the interaction between main effects (fixed effect), and $\varepsilon_{\mathrm{ijk}}$ is the random error.

The analyses were performed using the MIXED procedure of SAS $9.3(\alpha=0.05)$. The means were compared using Fisher's least significant difference.

\section{EVALUATION OF THE EXTRACTION OF CRUDE PROTEIN AND ASH}

To assess the extraction of the protein and ash components, two samples of forage (one grass and one legume) and one sample of cattle feces were randomly chosen. Five aliquots of each sample were subjected to fat extraction through the Randall method using cartridges made of qualitative filter paper and another five aliquots through the AOCS method using XT4 filter bags. The procedures were performed as described in section Quantification of the ether extract content.

Aliquots of the post-extraction residues and non-extracted samples were analyzed for crude protein (CP) and ash contents, according to the Kjeldahl method and by incineration in a muffle furnace $\left(600^{\circ} \mathrm{C} / 3\right.$ h), respectively (Detmann et al. 2012).

The $\mathrm{CP}$ and ash recoveries were estimated according to the following equation:

$$
R=\frac{M r}{M}
$$

where $\mathrm{R}$ is the recovery of $\mathrm{CP}$ or ash $\left(\mathrm{g} \mathrm{g}^{-1}\right), \mathrm{M}$ is the mass of $\mathrm{CP}$ or ash in the sample before extraction $(\mathrm{g})$, and $\mathrm{Mr}$ is the mass of $\mathrm{CP}$ or ash in the residue post-extraction $(\mathrm{g})$.

The recoveries of $\mathrm{CP}$ and ash $\left(\mathrm{g} \mathrm{g}^{-1}\right)$ were subjected to analysis of variance according to the model:

$$
Y_{i j}=\mu+S_{i}+M_{j}+\varepsilon_{i j}
$$

where $\mu$ is the general constant, $\mathrm{S}_{\mathrm{i}}$ is the random effect of the sample $\mathrm{i} ; \mathrm{M}_{\mathrm{j}}$ is the fixed effect of the extraction method $\mathrm{j}$ (Randall or AOCS), and $\varepsilon_{\mathrm{ij}}$ is the random error.

The analyses were performed using the MIXED procedure of SAS $9.3(\alpha=0.05)$. 


\section{RESULTS}

A significant interaction $(P<0.01)$ was observed between the extraction method and the assessed material relative to the EE contents (Table I). Higher EE contents were obtained with the AOCS method $(P<0.01)$ both for forage and cattle feces. However, the difference between the two methods was more prominent for the forage samples (Table II). There were no effects $(\mathrm{P}>0.05)$ associated to the containers (Table I).

There were no effects $(P>0.05)$ of the assessed material, container or their interaction on particle loss. The evaluation of the means suggested that the loss of particles was not significant in any of these containers $(P>0.05$, Table III).

There was an interaction effect $(P<0.05)$ between the evaluated material and the extraction method on the chlorophyll concentrations. The evaluation of this effect highlighted the differences $(P<0.01)$ between the extraction procedures for the forage samples only (Table IV). In this case, the comparison between the means suggested that, despite a small overlap, the AOCS method presented a lower concentration of residual chlorophyll $(P<0.05)$ compared to the Randall method. The concentrations obtained by both methods were below $(P<0.05)$ those obtained in the forages not subjected to extraction. There was no effect $(P>0.05)$ of the containers within each extraction method. (Table IV).

None of the estimates of $\mathrm{CP}$ and ash recovery were considered different from the parametric value $1(P$ $>0.05$ ), suggesting complete recovery of these components regardless of the extraction method (Table V).

TABLE I

Ether extract contents in forages and cattle feces according to extraction method and container type.

Extraction method

\begin{tabular}{|c|c|c|}
\hline Container $^{1}$ & Randall & AOCS \\
\hline & \multicolumn{2}{|c|}{ Forages (g/kg DM) } \\
\hline QFP & $21.0 \pm 3.9$ & $36.2 \pm 3.9$ \\
\hline \multirow[t]{2}{*}{ XT4 } & $20.8 \pm 3.9$ & $33.1 \pm 3.9$ \\
\hline & \multicolumn{2}{|c|}{ Cattle feces (g/kg DM) } \\
\hline QFP & $26.4 \pm 4.4$ & $30.1 \pm 4.4$ \\
\hline XT4 & $25.9 \pm 4.4$ & $33.4 \pm 4.4$ \\
\hline \multicolumn{3}{|l|}{$P$ value } \\
\hline \multicolumn{2}{|c|}{ Method of extraction (ME) } & $<0.001$ \\
\hline \multicolumn{2}{|c|}{ Container (C) } & 0.942 \\
\hline \multicolumn{2}{|c|}{ Material (M) } & 0.793 \\
\hline \multicolumn{2}{|c|}{$\mathbf{M E} \times \mathbf{C}$} & 0.708 \\
\hline \multicolumn{2}{|c|}{$\mathbf{M E} \times \mathbf{M}$} & 0.003 \\
\hline \multicolumn{2}{|c|}{$\mathbf{C} \times \mathbf{M}$} & 0.162 \\
\hline \multicolumn{2}{|c|}{$\mathbf{M E} \times \mathbf{C} \times \mathbf{M}$} & 0.133 \\
\hline
\end{tabular}

${ }^{1} \mathrm{QFP}=$ cartridges of qualitative filter paper; XT4 = filter bags XT4.
TABLE II

Evaluation of the interaction between method of extraction and evaluated material on ether extract contents.

\begin{tabular}{cccc}
\hline & \multicolumn{3}{c}{ Material (g/kg DM) } \\
\cline { 2 - 4 } Method & Forages & Cattle feces & $\boldsymbol{P}_{\text {value }}{ }^{2}$ \\
\hline Randall & $20.9 \pm 3.7$ & $26.2 \pm 4.2$ & 0.352 \\
\hline AOCS & $34.7 \pm 3.7$ & $32.3 \pm 4.2$ & 0.671 \\
\hline P value $^{1}$ & $<0.001$ & 0.001 & -- \\
\hline
\end{tabular}

${ }^{1}$ Descriptive level of probability for type I error associated with the differences between methods within each material. ${ }^{2}$ Descriptive level of probability for type I error associated with the differences between materials within each method.

TABLE III

Estimates of the loss of particles in forages and cattle feces according to the different containers.

\begin{tabular}{ccc} 
Container $^{1}$ & Loss of particles (g) & $\boldsymbol{P}_{\text {value }}{ }^{2}$ \\
\hline QFP & $0.0023 \pm 0.0047$ & 0.621 \\
\hline XT4 & $0.0024 \pm 0.0047$ & 0.613
\end{tabular}

${ }^{1} \mathrm{QFP}=$ cartridges of qualitative filter paper; XT4 = filter bags XT4. ${ }^{2} \mathrm{H}_{0}: \mu=0$. 
TABLE IV

Total chlorophyll concentration in forages and cattle feces and in the residues obtained after ether extract extraction using different methods.

\begin{tabular}{|c|c|c|}
\hline \multirow[b]{2}{*}{ Method $^{1}$} & \multicolumn{2}{|c|}{ Material (mg/kg DM) } \\
\hline & Forage $^{2}$ & Cattle feces \\
\hline Non-extracted & $1554 \pm 123 \mathrm{a}$ & $104 \pm 174$ \\
\hline $\mathbf{R}+\mathbf{Q F P}$ & $749 \pm 129 b$ & $113 \pm 193$ \\
\hline $\mathbf{R}+\mathbf{X T 4}$ & $610 \pm 123 b c$ & $61 \pm 175$ \\
\hline $\mathbf{A}+\mathbf{Q F P}$ & $466 \pm 123 c$ & $49 \pm 193$ \\
\hline $\mathrm{A}+\mathrm{XT} 4$ & $402 \pm 129 \mathrm{c}$ & $54 \pm 175$ \\
\hline$P$ value & $<0.001$ & 0.997 \\
\hline
\end{tabular}

${ }^{1}$ Non-extracted $=$ non-extracted samples; $\mathrm{R}=$ Randall method; $\mathrm{A}=\mathrm{AOCS}$ method; $\mathrm{QFP}=$ cartridges of qualitative filter paper; XT4 = filter bags XT4. ${ }^{2}$ Means in the column followed by different letters differ by the Fisher's Least Significant Difference at $P<0.05$.
TABLE V

Average recoveries of crude protein and ash according to the extraction method.

\begin{tabular}{ccc}
\hline \multicolumn{3}{c}{ Item $^{1}$} \\
\hline Method & Crude protein $(\mathrm{g} / \mathrm{g})$ & Ash $(\mathrm{g} / \mathrm{g})$ \\
\hline AOCS & $1.017 \pm 0.001(0.256)$ & $0.992 \pm 0.003(0.762)$ \\
\hline Randall & $1.013 \pm 0.001(0.369)$ & $1.002 \pm 0.003(0.936)$
\end{tabular}

${ }^{1}$ The values in brackets are the descriptive levels of probability for type I error associated with $\mathrm{H}_{0}: \mu=1$.

\section{DISCUSSION}

The use of the AOCS method produced higher estimates of the EE contents in both forages and cattle feces compared to the Randall method (Table II). These results corroborate those obtained by Silva et al. (2011) who compared the AOCS and Goldfish methods. Note that although the Randall method was developed to replace the Soxhlet method (Palmquist and Jenkins 2003), it appears to be more operationally similar to the Goldfish method.

The main differences between the AOCS method and the Randall and Goldfish extraction methods are the use of a pressurized environment and the use of XT4 filter bags. However, according to the data obtained in the present study, the use of XT4 filter bags did not influence the extraction, given that the results obtained with the filter bags were similar to those obtained with the use of cartridges of qualitative filter paper in all of the comparisons (Tables I, III and IV).

Considering the higher extraction of ether-soluble material using the AOCS method, the other assessments were conducted to understand the causes of the difference between the methods.

At first, it was hypothesized that the loss of particles by the use of XT4 filter bags could contribute to the higher estimates of the EE concentration. However, as previously noted, no differences were observed between the containers, given that both allowed non-significant loss of particles (Table III).

The total EE in a sample can be subdivided into two fractions. The first, called the fatty EE, is composed of the lipid fraction (triglycerides, galactolipids and phospholipids), which has nutritional interest. The second fraction, called the non-fatty EE, is composed of the remained non-polar components of the samples, including plant pigments, waxes and essential oils (Sukhija and Palmquist 1988, Van Soest 1994). The amount of non-fatty EE defines the difference between the analytical (EE) and biochemical (lipid) concepts of the fatty fraction of feed (Silva et al. 2011). 
The chlorophyll content was assessed based on the fact that it is a component of the non-fatty EE (Van Soest 1994). Therefore, the greater extraction of chlorophyll can be understood as an indicator of the greater capacity of the method to extract non-fatty EE. Thus, from the results obtained in the present study, it can be inferred that the AOCS method promotes greater extraction of non-fatty material in forage samples, due to the lower concentration of chlorophyll in the material subjected to extraction (Table IV). Similar results were obtained by Silva et al. (2011). This could explain the differences between the methods for the contents of total EE (Table II). However, there was no difference in the chlorophyll content for the samples of cattle feces (Table IV).

In the study of the interaction between the extraction method and evaluated material, it was observed that the difference between the methods is more prominent for forage samples (Table II). Thus, considering that there was a smaller difference for the fecal samples and that there was no change in the chlorophyll concentration in the feces, there possibly was extraction of non-fatty material with characteristics different from that of pigments, which could explain the difference between the methods in the cattle feces and would complement the difference between the methods for the forage samples.

According to Van Soest (1994) some components of the non-fatty EE, including essential oils and low molecular weight phenols, can be absorbed and subsequently excreted in the urine. Thus, by being absorbed, they do not compose the fecal EE, which would help explain the smaller difference between the methods for the cattle feces samples.

However, comparisons between the materials in the present study should be interpreted with caution, given that the fecal samples do not match those that would be obtained in diets predominantly composed of the forages evaluated here. Thus, the total composition of the non-fatty EE obtained by the Randall and AOCS methods remains undefined. However, regardless of the limitations, the results suggest that there is a higher extraction of non-fatty materials using the AOCS method.

Water-soluble substances (e.g., sugars, amino acids and salts) may be extracted together with the non-polar materials in some cases (Pomeranz and Meloan 1978, Palmquist and Jenquins 2003), which could increase the non-fatty EE fraction. Thus, we evaluated the possible extraction of polar material by analyzing the recovery of nitrogenous and ash compounds. However, due to the complete recovery of both groups of compounds (Table V), it was understood that there was no extraction of polar material by the Randall and AOCS methods.

In conclusion, it can be stated that quantification of the EE contents in forage and cattle feces samples through the AOCS Am 5-04 method provides higher estimates than those obtained by the Randall method, possibly due to greater extraction of non-fatty EE. There are no influences on the estimates of the EE contents related to the use of XT4 filter bags and cartridges of qualitative filter paper $\left(80 \mathrm{~g} / \mathrm{m}^{2}\right)$.

\section{ACKNOWLEDGMENTS}

The authors would like to thank the Conselho Nacional de Desenvolvimento Científico e Tecnológico (CNPq), Coordenação de Aperfeiçoamento de Pessoal de Nível Superior (CAPES), Fundação de Amparo à Pesquisa do Estado de Minas Gerais (FAPEMIG), and Instituto Nacional de Ciência e Tecnologia de Ciência Animal (INCT Ciência Animal) for the financial support. 


\section{REFERENCES}

AOCS - AMERICAN OIL CHEMISTS' SOCIETY. 2009. Official methods and recommended practices of the AOCS, 6th ed., Denver: AOCS.

DETMANN E, SOUZA MA, VALADARES FILHO SC, QUEIROZ AC, BERCHIELLI TT, SALIBA EOS, CABRAL LS, PINA DS, LADEIRA MM AND AZEVÊDO JAG. 2012. Métodos para análise de alimentos - Instituto Nacional de Ciência e Tecnologia em Ciência Animal, Visconde do Rio Branco: Suprema, 214 p.

LICHTHENTHALER HK. 1987. Chlorophylls and carotenoids: pigments of photosynthetic biomembranes. In: Collowick SP and Kaplan NO (Eds), Methods in enzymology, San Diego: Academic Press, p. 350-382.

PALMQUIST DL AND JENKINS TC. 2003. Challenges with fats and fatty acid methods. J Anim Sci 81: 3250-3254.

POMERANZ Y AND MELOAN CE. 1978. Food analysis: theory and practice. Westport: Avi Publishing, 778 p.

SILVA PT, DETMANN E, VALADARES FILHO SC, DETMANN KSC, BARROS LV, MARTINS SCV, MORAIS LE AND COSTA VAC. 2011. Evaluation of total and non-fatty ether extract in feeds and cattle feces using two analytical methods. Anim Feed Sci Technol 163: 111-117.

SUKHIJA PS AND PALMQUIST DL. 1988. Rapid method for determination of total fatty acid content and composition of feedstuffs and feces. J Agric Food Chem 36: 1202-1206.

THIEX NJ, ANDERSON S AND GILDEMEISTER B. 2003. Crude fat, diethyl ether extraction, in feed, cereal grain, and forage (Randall/Soxtec/Submersion Method): collaborative study. J AOAC Internat 86: 888-898.

VAN SOEST PJ. 1994. Nutritional ecology of the ruminant, 2nd ed., Ithaca: Cornell University, 476 p. 